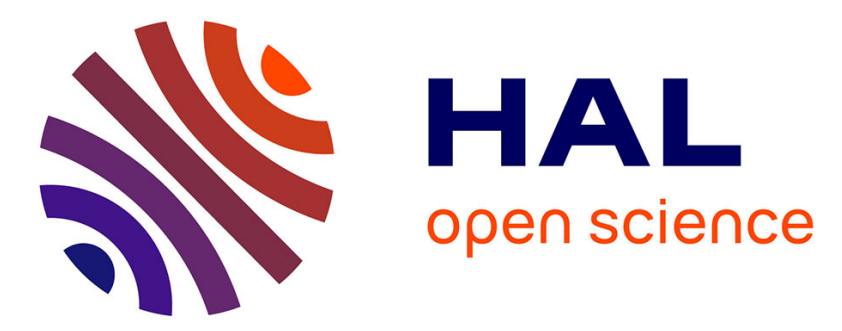

\title{
Error Generation, Inventory Record Inaccuracy (IRI) and Effects on Performance: A Dynamic Investigation
}

Wissam El Hachem, Ramy Harik, Joseph Khoury

\section{To cite this version:}

Wissam El Hachem, Ramy Harik, Joseph Khoury. Error Generation, Inventory Record Inaccuracy (IRI) and Effects on Performance: A Dynamic Investigation. 13th IFIP International Conference on Product Lifecycle Management (PLM), Jul 2016, Columbia, SC, United States. pp.642-651, 10.1007/978-3-319-54660-5_57. hal-01699677

\section{HAL Id: hal-01699677 \\ https://hal.inria.fr/hal-01699677}

Submitted on 2 Feb 2018

HAL is a multi-disciplinary open access archive for the deposit and dissemination of scientific research documents, whether they are published or not. The documents may come from teaching and research institutions in France or abroad, or from public or private research centers.
L'archive ouverte pluridisciplinaire HAL, est destinée au dépôt et à la diffusion de documents scientifiques de niveau recherche, publiés ou non, émanant des établissements d'enseignement et de recherche français ou étrangers, des laboratoires publics ou privés. 


\title{
Error Generation, Inventory Record Inaccuracy (IRI) and Effects on Performance: A Dynamic Investigation
}

\author{
Wissam EL Hachem¹, Ramy Harik², Joseph Khoury ${ }^{3}$ \\ ${ }^{1}$ Department of Operations Management, ESSEC Business School, Paris, France \\ Wissam.elhachem@essec.edu \\ ${ }^{2}$ Department of Mechanical Engineering, School of Engineering and Computing, University \\ of South Carolina, Columbia, South Carolina, USA \\ harik@cec.sc.edu, \\ ${ }^{3}$ Methode Electronics Inc.,Gau-Algesheim, Germany \\ Joseph.khoury@methodegermany.com
}

\begin{abstract}
One of the aspects of a good inventory control system is low Inventory Record Inaccuracy (IRI). IRI control ought to be an integral part of PLM by helping to further streamline the production, transportation and service stages. This paper contributes to the expanding debate on linking error generation to Inventory Record Inaccuracy (IRI) and its ensuing effects on performance. Methods of discovering and eliminating the root causes of IRI are presented. A System Dynamics (SD) simulation model is used to examine and confirm the substantial impact of error generation and IRI on workflow. The results of the model show that even a small undetected source of IRI can accumulate and eventually destabilize the entire system.
\end{abstract}

Keywords: Supply Chain, Inventory Control, Error Generation, Inventory Record Inaccuracy, System Dynamics

\section{Introduction}

Inventory management is of prime importance for businesses with any kind of inventory, especially those that deal with physical assets. Inventory management and Product Lifecycle Management (PLM), which include production and transportation stages of a product, are closely related where the former is an integral part of the latter. In this paper, the focus is on manufacturing and assembly plants and their inventory management techniques, specifically, record inaccuracies and performance measurements. Companies base their inventory and production decisions on inventory reports of stock levels as generated by information systems. These reports could have errors as discrepancies between actual inventory levels and reported system levels are often reported ([2], [12]). The issue of record inaccuracy is not limited to manufacturing industry alone as it is also prevalent in sectors such as retailing and banks. Inventory Control and in particular Inventory Record Accuracy are central to 
any supply chain initiative and their success is a pre-requisite for supply chain collaboration initiatives. Inaccurate inventory records cause a significant drop in company's profits by as much as millions of dollars ([7], [11]). This is caused by either excess or shortage in inventory of certain parts which eventually leads to low service levels. Hence, controlling IRI is crucial in PLM.

This paper will contribute to the emerging debate on the effects of Inventory Record Inaccuracy (IRI) on performance. It will do so by thoroughly defining and discussing IRI in section 2 before presenting a System Dynamics model to investigate the dynamics of error generation and its impact on performance in section 3 . Contributions and limitations are outlined in section 4 before concluding in section 5 .

\section{Inventory Record Inaccuracy (IRI)}

Inventory management can be complex in nature. Practices such as $A B C$ and similar ones are important yet they are not capable of forecasting the dynamics involved in inventory management. Some programs like MRP and ERP are quite effective in controlling inventory. But, in addition to these programs, dynamic production simulation models could also be beneficial. They offer a more holistic view as seen through hands-on model building experience which helps users to understand unique nuances of the systems adopted in their respective company. An example of such simulation models will be discussed in section 3 .

Along with simulation tools, inventory scanning technologies have also proven to be useful, in particular, Radio Frequency Identification (RFID). For inventory control, case-level tagging has the best quality-to-cost ratio [3].

Mere implementation of the cited inventory control systems is insufficient to yield good results. All these systems are dependent on the availability of accurate information including identity, status and location of components. Having inaccurate records will result in wrong order decisions (overstocking or under stocking) which jeopardizes the profits of the company.

\subsection{What is IRI?}

IRI is the discrepancy between the system level and the actual level of inventory. There could be overstated inventory when the systems show more than the physical inventory or understated inventory when the systems show less than actual physical inventory levels in the stores [8]. The ratio of over and understated inventory varies between different types of businesses, however quite often they are equal ([5], [6]). There are two types of variance, Net Variance (eq.1) and Gross Variance (eq.2), as well as two measurements types, dollar based and count based.

$$
\begin{aligned}
\text { Net Variance } & =\sum(\text { System Inv Level }- \text { Store Inv Level }) . \\
\text { Gross Variance } & \left.=\sum \text { abs (System Inv Level }- \text { Store Inv Level }\right) .
\end{aligned}
$$


Dollar based measurements are typically used by auditors in their calculations at an aggregate level, where overstated and understated discrepancies do not matter as long as they almost cancel each other out. This is similar to the Net Variance construct. Count based measurements are typically used by operations managers to maintain an accurate view of their stock keeping unit (SKU) levels. Count based is similar to the Gross Variance construct.

\subsection{Importance of IRI}

IRI tracking has financial as well as operational benefits. Some of the financial reasons are minimizing over or under payment of taxes and thus avoiding negative economic repercussions [10]. There are several operational reasons to support the importance of IRI tracking. First, inaccurate records will eventually lead to stockouts (Overstated levels generate phantom inventory delaying the trigger to order new inventory) or overstocking (understated levels leads to hidden inventory and the ordering of excessive levels) [9]. Second, fixing inventory records is time and labor consuming reducing efficiency. Third, production control systems are very much sensitive to IRI [1]. Fourth, inventory control software such as ERP requires high inventory accuracy (above $95 \%$ ).

\subsection{Causes of IRI}

Inventory record inaccuracy has many root causes. Most of them are either process related or volume related. In the process related category, with every step in the manufacturing and allied processes, there is a probability of error. Ways to reduce errors include reducing number of transactions and simplifying processes as much as possible. In the volume related category, larger volumes imply more transactions, and consequently more chances of errors. To reduce source of errors, methods such as backflushing, bill of material (BOM) simplification and Kanban can be adopted.

Figure 1 presents a causal loop diagram (CLD) depicting some of the dynamics of inventory record errors. A causal loop diagram (CLD) links variables that have a hypothesized direct or indirect causal relationship to a target variable whose behavior is being investigated. A model of inventory error generation will be discussed in section 3 .

A company has several ways to improve inventory accuracy. Some firms tackle this issue by eliminating the root causes and some others aim for better error discovery and correction. This is done through cycle counting (Geographic method, Random Sampling, $\mathrm{ABC}$...), stocktaking (Quarterly or Yearly), control charts (particularly attribute charts), investigating behavioral root causes (prominent in activities such as Order Picking) and transaction reduction (simpler BOM's, Kanban, Backflushing). 


\section{Dynamic Behavior and Performance Measurement}

The dynamics in inventory management are complex and therefore, simulation is needed for better control. MRP and ERP are widely used software that are quite efficient in inventory management. However, these software applications most often require customization to fit the needs of particular firms. This could be problematic as their users might introduce complicated constraints and objectives if they do not perfectly understand the underlying logic behind these applications. In this section we will present a sample simulation model that follows the methodology of System Dynamics (SD). The model will present a structure that partially explains error generation and has the potential to advance a firm's knowledge of its inventory system by offering a "hands-on" model building experience.

Error generation with regard to inventory records is quite complex and it has many different root causes as well as many different solutions. A simple model that follows the System Dynamics (SD) methodology has been constructed that illustrates error generation inside a company and its impact on work completion given limited resources (mainly workers). The structure of the model can be applied to both operational errors for manufacturing throughput as well as to warehousing, shipping and receiving errors for IRI. This paper will apply the model within an IRI context.

The basic concept of the model is that a company has a certain number of units to process per month. There are errors in the processing which results in under $100 \%$ completion rate along with additional rework even after costly workforce expansion and improvement programs. The model tackles some of the loops in the inventory dynamics model using the causal loop diagram (CLD) as given in Figure 1. The stocks and flows $(\mathrm{S} \& \mathrm{~F})$ model was built using the iThink software and its CLD is given in Figure 2. 
Model Explanation Every two variables are linked together by an arrow which has either a positive "+" or a negative "-" polarity (Figure 3). The sign of the polarity is determined following the "ceteris paribus" principle, meaning by setting everything else as constant. The "+" polarity as in Figure 3 means that if Variable A increases, Variable B will increase and vice versa. The "-" polarity means that if Variable C increases, Variable D will decrease and vice versa.

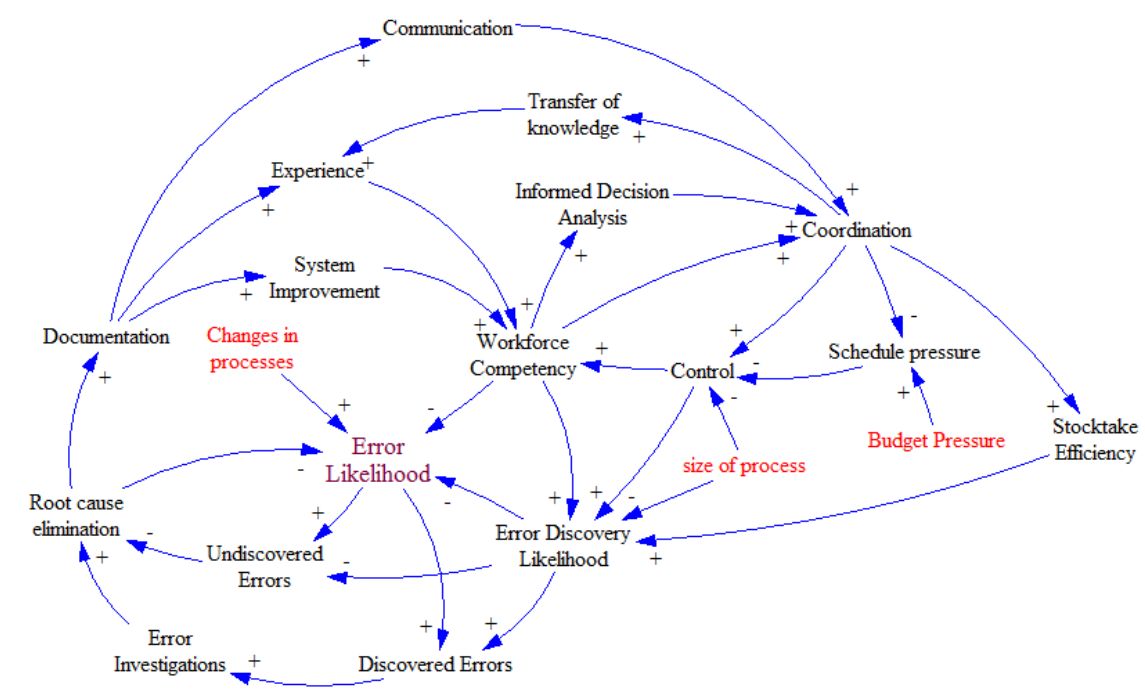

Fig. 1. Inventory Record Error Dynamics 


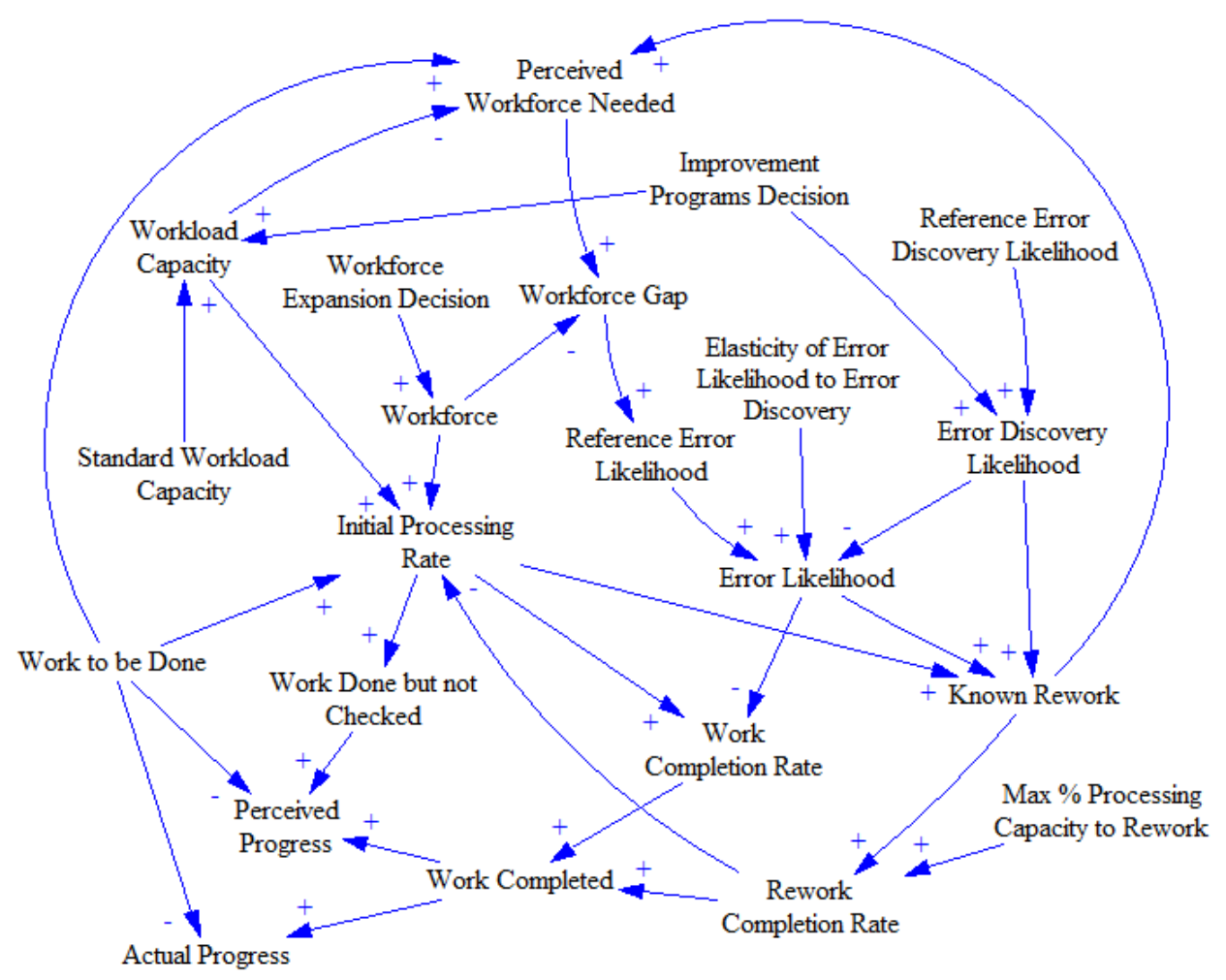

Fig. 2. Error Generation CLD

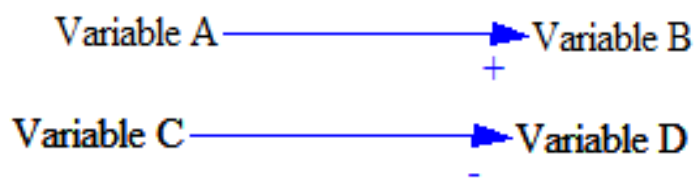

Fig. 3. CLD Polarity

The main components of the model are explained next. Every worker has a standard workload capacity (for example 20 units/employee) that he/she can process per month. Given a certain workforce number (for example 100 employees), a certain processing capacity is determined (in our example its 2000 units). Given a certain volume of work to be done and a workload capacity, a certain number of workforce is perceived able to finish the work (here its 100 employees).

Based on this, the company can choose to modify its current number of workers to match with the perceived workforce number or to leave it constant as it is. A positive gap between the needed number of workers and the actual number will result in an increased pressure on the existing workers and will lead to an increase in error generation: 
A minimum $5 \%$ reference error likelihood is present even when gap is zero to account for the many other sources of error generating factors. A maximum limit of $25 \%$ errors is placed to keep error generation levels to a reasonable level. These error levels can be changed to suit each specific industry and its production lines/methods.

There is as an error discovery likelihood that counteracts error generation. The reference error discovery likelihood is placed at $90 \%$, which implies that $90 \%$ of all errors can be discovered.

Since there are errors in the processing of the units with a $90 \%$ error discovery rate, there will be known rework. The known rework will require processing again. It is assumed that all of the rework will be done correctly with no possibility for errors at this stage. The rework will require some of the workers to devote their time to it. It is assumed that rework will have priority over initial processing, meaning if there are workers available, some or all of them will be devoted to rework.

In the model, there is a "max \% processing capacity to rework" that limits the percentage of workers that will devote their time for rework. Currently it is set to a full $100 \%$. So if there are 10 workers available, and there is rework that requires 10 workers, all workers will be devoted for the rework. This can be modified if needed in the structure of the model by setting a "max \% processing capacity to rework" lower than 1. Hence the initial processing rate has to take into account the rework completion rate.

The units that are successfully processed from the beginning are the "work completion rate". Work completed will be summation of both the work completion rate and of the rework completion rate:

Work completed $=$ rework completion rate + work completion rate.

Out of the total errors that are generated, $90 \%$ of them are discovered. Meaning $10 \%$ of the errors are not discovered by the company and will wrongfully show up as completed. Hence a discrepancy between perceived progress and actual progress arises:

$$
\begin{gathered}
\text { Perceived Progress }=(\text { work done but not checked }+ \text { work completed }) \div \\
\text { Cumulative Work to be done. }
\end{gathered}
$$

$$
\text { Actual Progress }=\text { work completed } \div \text { cumulative work to be done }
$$

If there is a 5\% error likelihood with $90 \%$ error discovery likelihood, then $0.5 \%$ of the work is never properly done, which will cost the company a lot of money either in lost revenue or added expenses of costly rework. Perceived progress is an erroneous $100 \%$ if there is no workforce gap.

The company will need to deploy some strategy to counteract the error generation. In this model, the major driver of error generation is the workforce gap. Hence the company has to always make sure that it has enough workers to handle the amount of work to process. The two main feedback loops of error generation in the model are presented in Figure 4.

One Loop is a Reinforcing Loop for Known Rework, meaning an increase in the Known Rework will lead to an even bigger increase later on. The other loop is a Balancing loop, meaning an increase in Known Rework will lead to its decrease later 
on. The two policies of Improvement Programs and Workforce Expansion are also illustrated in Figure 4 with red links. The two policies work as follows:

- Workforce expansion: Even with an initial gap of zero, given a minimum 5\% error likelihood, there will be rework to be done which would require workers. Hence the need to hire more people. This would keep the gap at zero keeping the error percentage from rising above $5 \%$.

- Improvement programs: Improvement programs could involve one or more of the following methods: lean manufacturing techniques, new scanning technology, or stocktake standardization. Lean techniques and new scanning technology would increase workload capacity as well as error discovery.

If improvement programs are introduced, workload capacity is increased by one additional unit to 21 units/employee which would increase the Initial processing rate and decrease the perceived workforce needed. Also, error discovery would increase by 5\% increasing Known Rework. By increasing error discovery, error likelihood would drop as well.

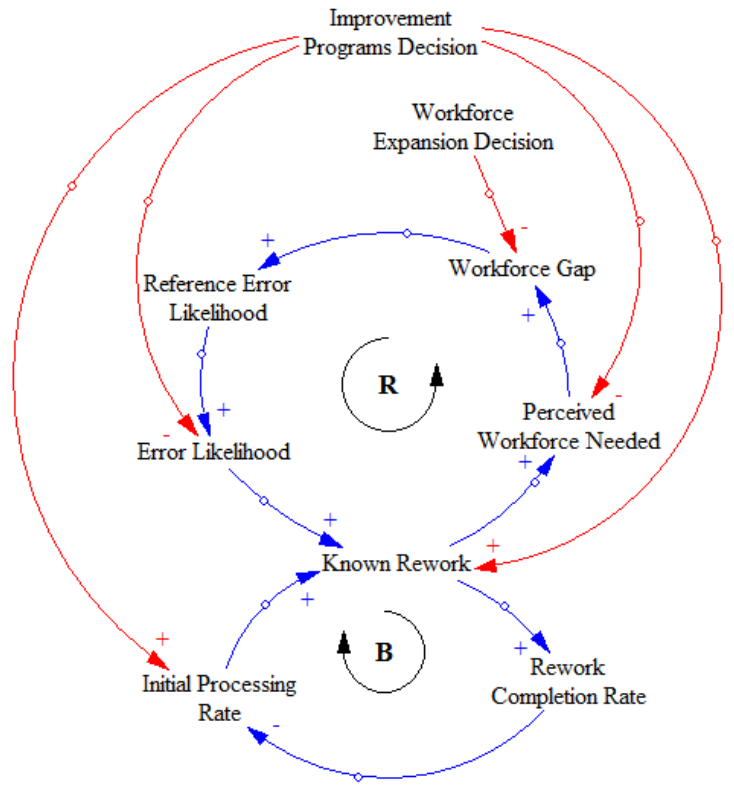

Fig. 4. Error Generation Main Loops and Policies

The Improvement Programs policy will strengthen the balancing loop by increasing the Initial Processing Rate as well as increasing known rework through higher error discovery. This policy however will have a conflicting role concerning the reinforcing loop. It will decrease the Perceived Workforce Needed as well as the Error Likelihood slowing down the reinforcing loop while strengthening it by increasing the Initial Processing Rate and Known Rework. One or both of these policies should be implemented from the start to prevent an escalation in error generation. 
Model Behavior Let us run the model for 36 months under different scenarios. Please note that this model does not take into consideration constraints such as hiring, firing and training times. Figures 5 and 6 show the outcomes.

Scenario 1 is for Workforce Expansion: If the company decides to hire more people from the beginning to close the gap between workforce and perceived workforce needed, the actual progress would fall before rising back to 0.993 by the end. The perceived workforce needed would increase to 127 before falling back to 105.

Scenario 2 is for Improvement Programs: If the company decides to implement improvement programs from the beginning (it is assumed that they are effective immediately), the actual progress would stay constant at 0.9974 which is the maximum progress that can be made given the undiscovered errors. The perceived workforce needed is a constant at 99 because the workload capacity is now higher.

Scenario 3 is when both policies are delayed by 5 months: If the company decides to delay its workforce expansion and improvement programs policies by 5 months, the actual progress would fall to 0.798 before rising back up to 0.995 . The perceived workforce would increase to 170 before falling back down to 99 .

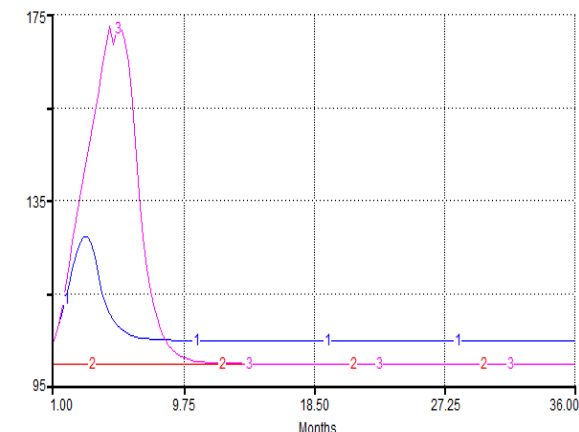

Fig. 5. Workforce Needed Scenarios

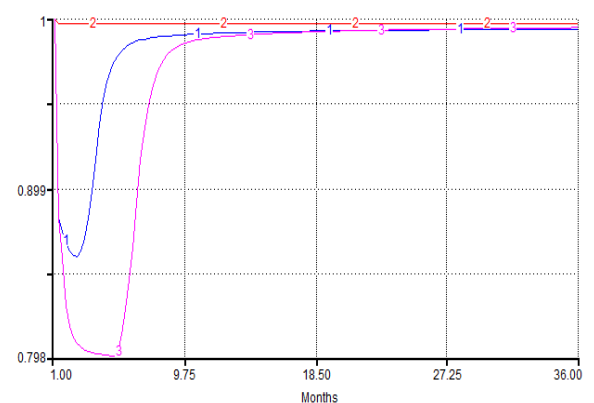

Fig. 6. Actual Progress Scenarios

In scenario 3 with a delay of 5 months before implementing the policies, errors would accumulate leading to higher error likelihoods which would require even more workers to devote their time to rework, thereby reducing the initial processing capacity and increasing the work to be done.

\section{Contributions and Limitations}

The paper presents a detailed yet concise overview of IRI with all the key terms and techniques that one might need. This is a rarely discussed topic in the literature and hence the paper would prove useful to researchers and managers.

The paper presents novel and relevant diagrams and models in section 3 that offer insights into the dynamics at play in error generation and IRI. The results of the error 
generation and IRI models with the suggested policies help the reader in understanding the complexity of the topic and how simple and small errors can lead to big repercussions. However these are initial models and they portray simplified realities where some of the constraints have been relaxed. Further efforts are still needed to capture and incorporate more of the dynamics involved into the presented models. Mental models at play in such complex environments might provide crucial tips into the root causes of such discrepancies [4]. The challenge would be how to capture all of these factors while preserving the simplicity of the models and their ability to offer actionable analytics for practitioners. Naturally, optimization efforts to achieve the best mix of different performance indicators are the next step after having finalized the structure of the models.

As a next step, the presented model can be incorporated into larger models which represent entire supply chains and consequently the transportation and service stages of PLM would be tackled as well versus only the production stage in this paper.

\section{Conclusions}

Inventory control is fundamental for any company that deals with any kind of inventory. An implicit assumption of perfect information on the state of the inventory given by inventory information systems has been proven to be wrong. Error generation which leads to IRI have many root causes and there are several methods to counter-act it. Every company has to consider each of these methods such as cycle counting, stocktaking and simulation in its efforts to minimize IRI. This paper compiles some of the techniques that can be used in these efforts and it presents as well models that capture some of the dynamics that give rise to error generation and IRI. It is important to recognize that perfect information is not possible and zero errors is an idealistic goal that could backfire by setting off a vicious dynamic chain of reactions. A properly conceived plan has to be carefully set with the help of simulation tools. This would improve our understanding of the repercussions of policies and bridge the gap between achieved results and desired goals.

\section{References}

1. Chan, F., and Wang, Z. Robust production control policy for a multiple machines and multiple product-types manufacturing system with inventory inaccuracy. International Journal of Production Research, 52(16): 4803-4819 (2014)

2. DeHoratius, N. and Raman, A. Inventory Record Inaccuracy: An Empirical Analysis. Management Science, 54(4):627-641 (2008)

3. Delen, D., Hardgrave, B., and Sharda, R. RFID for better supply-chain management through enhanced information visibility. Production and Operations Management, 16(5):613-624 (2007)

4. EL Hachem, W., Khoury, J., Harik, R. Mental Model Moderation Modification and Managing (5M) Framework: A System Dynamics and Brunswikian Lens Model Approach to Complex Decision Making. Proceedings of International Conference on Industrial Engineering and Operations Management, IEEE, Dubai, 1-10 (2015) 
5. Hardgrave, B., Aloysius, J., and Goyal, S. RFID-Enabled Visibility and Retail Inventory Record Inaccuracy: Experiments in the Field. Production and Operations Management,22(4): 843-856 (2013)

6. Hardgrave, B., Aloysius, J., and Goyal, S. Does RFID improve inventory accuracy? A preliminary analysis. International Journal of RF Technologies, 1(1):44-56 (2008)

7. Hollinger, R.C. and Davis, J.L. National Retail Security Survey Report. Department of Sociology and the Center for Studies in Criminology and Law, University of Florida (2001)

8. Khader, S., Rekik, Y., Botta-Genoulaz, V., and Campagne, J. Inventory management subject to multiplicative inaccuracies. International Journal of Production Research, 52(17): 5055-5069 (2014)

9. Nachtmann, H., Waller, M., and Rieske, D. The Impact of Point-Of-Sale Data Inaccuracy and Inventory Record Data Errors. Journal of Business Logistics, 31(1):149-158 (2010)

10. Rekik, Y., and Sahin, E. Exploring inventory systems sensitive to shrinkage - analysis of a periodic review inventory under a service level constraint. International Journal of Production Research, 50(13):3529-3546 (2012)

11. Rossetti M.D., Buyurgan N., Bhonsle A., Gumrukcu S., and Chittoori K. An Analysis of the effect of inventory record inaccuracy in a two-echelon supply chain. International Journal of Inventory Research, 1(2):174-208 (2010)

12. Raman, A., DeHoratius, N., and Ton, Z. Execution: The missing link in retail operations. California Management Review, 43(3): 136-152 (2001) 